\title{
HIKMAH PENURUNAN AL-QUR'AN SECARA BERANGSUR
}

\author{
Maulana Dwi Kurniasih, Dyah Ayu Lestari, Ahmad Fauzi \\ Institut Perguruan Tinggi Ilmu al-Qur'an (PTIQ), Indonesia \\ Email: kurniasihd6@gmail.com
}

\begin{abstract}
The verses of the Qur'an are not revealed as a whole at once, but gradually. The letters he sent were not the same in length and in short, sometimes they were sent in full and sometimes only in part. Through the study of literature, the article concludes that the gradual revelation of the Qur'an a lot of wisdom that will be obtained that is to set the heart of the Prophet, weaken his opponents, easy to understand and memorize, the arrangement will be in accordance with traffic events. The gradual revelation of the verses of the Qur'an gives some wisdom among them: strengthening the heart of the Prophet Mubammad SAW; Easy to memorize and understand; the believers are enthusiastic in accepting the Qur'an and actively practicing it; Accompanying events in society and gradually in establishing a law; weakening his opponents (miracles), and challenging the disbelievers who deny the Qur'an.
\end{abstract}

Keywords: Wisdom; the Qur'an, gradually; Prophet Mubammad; Muslims;

Abstrak. Ayat-ayat al-Qur'an tidaklah diturunkan keseluruhan sekaligus secara, tetapi secara berangsur-angsur. Suratsurat yang diturunkanya pun tidak sama jumlah panjang dan pendeknya, terkadang diturunkan sekaligus secara penuh dan terkadang sebagianya saja. Melalui kajian pustaka, Artikel menyimpulkan bahwa diturunkanya al-Qur'an secara berangsur-angsur banyak hikmah yang akan diperoleh yaitu menetapkan hati Rasulullah, melemahkan lawanlawannya, mudah difahami dan dihafal, penyusunannya akan sesuai dengan lalulintas peristiwa atau kejadian. Penuruan ayat al-Qur'an secara beransur memberikan beberapa hikmah diantaranya: menguatkan hati Nabi Muhammad Saw; Mudah dihafal dan dipahami; orang-orang mukmin antusias dalam menerima Qur'an dan giat mengamalkannya; Mengiringi kejadian-kejadian di masyarakat dan bertahap dalam menetapkan suatu hukum; melemahkan lawan-lawannya (mukjizat), dan menantang orang-orang kafir yang mengingkari al-Qur'an.

Kata Kunci: Hikmab; al-Qur'an, berangsur; Nabi Muhammad, Umat Islam; 


\section{Pendahululan}

Allah menurunkan Alquran kepada Nabi Muhammad SAW sebagai sumber ajaran Islam dan juga sebagai way of life. Turunnya Alquran merupakan peristiwa besar sebagai satu- satunya wahyu yang masih ada hingga sekarang ini. Sebagai verbum-dei (kalam Allah), Alquran mencangkup spiritualitas dan doa Muhammad yang berasal dari substansi eksistensi keRasullan nya melalui firman Allah ke dalam jiwa Rasul yang suci. Kandungan pesan Illahi yang disampaikan Nabi pada permulaan abad ke-7 itu telah meletakkan basis untuk kehidupan individual dan social kaum muslimin dalam segala aspeknya (Wahid, 2005).

Nuzulul Qur'an adalah peristiwa awal turunnya Alquran dari "Lauh Mahfudz, ke Langit Dunia" kepada Nabi Muhammad SAW secara bertahap atau tidak di turunkan sekaligus (jumlah wahidah), namun di turunkan secara berangsur-angsur (munajjaman). Turunnya ayat pertama Alquran yakni Surat Al Alaq ayat 1-5 melalui perantara malaikat Jibril, di Gua Hira, Jabal Nur. Adapun waktu turnnya Alquran sendiri berbagai pandangan pendapat berbeda- beda. Penurunan Alquran secara gradual adalah fase yang memegang peranan penting dalam efektivitas dakwah agama Islam. Islam dengan mudah diterima dan diserap oleh manusia dengan penurunan wahyu yang tidak sekaligus. Dan Alquran diturunkan di dua kota yaitu Mekkah dan Madinah dengan mempertimbangkan latarbelakang sosio, kultur dan grafis masyarakat.

Dalam beberapa doktrin teologis dikatakan bahwa sebelum diturunkan, Alquran telah tersimpan di dalam Laub al-Mahfudz (Q.S. Al-Buruj: 21-22), yaitu catatan gaib yang sangat besar, detail dan kompleks tentang segala sesuatu yang tercipta-baik yang ada, akan ada dan sudah tiada (Madya,2008). Catatan ini telah tertulis sejaka zaman Azali Izzah yang berada di lapisan langit terdekat dengan bumi (Sama'ad dunya), kemudian diturunkan oleh malaikat Jibril secara gradual atau tidak secara sekaligus sesuai kebutuhan. Bahkan wahyu turun untuk menjawab pertanyaan para sahabat yang dilontarkan kepada Nabi atau untuk membenarkan tindakan Nabi Muhammmad SAW (Anwar, 2007).

Adapun pengertian Alquran menurut istilah yang telah disepakati ulama adalah "Kalam Allah yang bernilai mukjizat yang diturunkan kepada Nabi Muhammada SAW dengan perantara malaikat Jibrl AS, yang tertulis pada mashahif, diriwayatkan kepada kita secara mutawatir Ash-Shabuni, h.3).

Alquran adalah kitab Allah yang berisi kalam dari Yang Maha Suci, mukjizat Nabi Muhammad SAW yang abadi, di turunkan kepada seorang Nabi yang terakhir yaitu Nabi Muhammad SAW, penutup para Nabi dan Rasul. Dan Alquran berfungsi sebagai petunjuk manusia dalam menghadapi belbagai situasi- kondisi dan persoalan hidup. Ayat-ayat dalam Alquran di turunkan dalam keadaan dan waktu yang berbeda. Bagi Alquran, walaupun di antara ayatnya yang turun didahului oleh sebab tertentu, tetapi sebab disini secara teoritis tidak mutlak adanya, walaupun secara empiris telah terrjadi persitiwa adanya sebab Nuzul Qur'an (Baidan, 2005).

Mempelajari Alquran adalah kewajiban bagi seorang muslim. Karena, Alquran adalah kitab suci kaum muslimin yang menjadi sumber ajaran Islam yang pertama dan utama. Kitab suci yang harus kita imani dan aplikasikan dalam kehidupan agar memperoleh kebaikan di dunia dan di akhirat. Karena itu, hendakny a kita tidak hanya mempelajari isi dan pesan- pesannya, tetapi juga berupaya semaksimal mungkin untuk menjaga otentitasnya (Athaillah, 2010,1). 


\section{Pengertian Nuzulul Quran}

Alquran adalah kitab Allah yang berisi Kalam dari Yang Maha Suci, mukjizat Nabi Muhammad SAW yang abadi, di turunkan kepada seorang Nabi yang terakhir yaitu Nabi Muhammad SAW, penutup para Nabi dan Rasul. Dan Alquran berfungsi sebagai petunjuk manusia dalam menghadapi belbagai situasi- kondisi persoalan hidup. Ayat-ayat dalam Alquran di turunkan dalam keadaan dan waktu yang berbeda. Bagi Alquran, walaupun di antara ayatnya yang turun didahului oleh sebab tertentu, tetapi sebab disini secara teoritis tidak mutlak adanya, walaupun secara empiris telah terrjadi persitiwa adanya sebab Nuzul Qur'an (Baidan, 2005, 132).

Nuzulul Qur'an diungkap dengan ungkapan yaitu: kata Nazzala-yunazzilu-tanzilan dengan makna "turun secara berangsur-angsur dan kata an₹ala-yun₹ilu-inzalan dengan makna denotative "menurunkan". Ketika kita menempatkan arti an-nuzul secara Bahasa kepada Alquran maka ditemukan arti-arti tersebut tidak layak untuk disematkan ke dalam Alquran kecuali dalam bentuk majas (Chirizin, 1998, 14). Alquran sebagai al-kalam an-nafsi yang terdapat dalam zat Allah, maka tidak layak dimengerti an-nuzul secara Bahasa. Karena arti tersebut hanya sesuai untuk al-hawadist (baharu), sedangkan zat Allah suci. Jika Alquran dipandang sebagai Lapaz yang dibaca, maka tidak layak dimengerti sebagai kata an-nuzul secara Bahasa juga. Karena lapaz bersifat "aradb” yang keberadaannya hanya diketahui saat diucapkan. Maka jalan keluar bagi pengertian an-nuzul secara Bahasa, ditempatkannya secara bentuk majas artinya adalah "menginformasikan, menetapkan, menggerakkan dari atas ke bawah".

Kata nuzul menurut Bahasa bagi para ulama juga mempunyai arti yang berbeda antara lain sebagai berikut: Pertama, Imam Ar- Raghib al-Asfihfani dalam kitabnya al- Mufradaat kata nuzul itu mempunyai arti: $A l$ - inbidar min'uluwmin ila safalin (meluncur dari atas ke bawah atau berarti turun) sesuai dengan firman Allah SWT dalam Surat Al Baqarah ayat 22 yaitu:

"Dan Dia menurunkan air (bujan) dari langit." (Q.S. Al Baqarah: 2/22)

Kedua, Imam al-Fairuz Zabadi dalam kamusnya Al-Mubith Al-Hulul Fi Makan, kata Nuzul itu mempunyai arti "bertempat di suatu tempat" contohnya antara lain dalam firman Allah SWT dalam surat Al Mu'minuun: 29 yaitu:

"Dan berdoalah: Ya Tuhanku, tempatkanlah aku pada tempat yang diberkabi dan Engkau adalah sebaik-baiknya yang memberi tempat." (Q.S. Al Mu’minuun: 23/29)

Menurut ulama yakni tokoh golongan "Jahamiyah" dan Ibn Taimiyah mengatakan bahwa dalam mengartikan kata Nuzul itu tidak perlu harus meninggalkan arti yang hakiki, yakni berarti turun dan tidak harus menggunakan arti majasi. Karena kata Nuzul dengan arti turun dari tempat yang tinggi itu sudah menjadi kebiasaan orang Arab. Contonya sesuai dalam firman Allah SW'T surat Al A'raf ayat 26:

"Hai anak. Adam, Sesunggubnya Kami telah menurunkan kepadamu pakaian untuk menutup auratmu dan pakaian indah untuk perbiasan. dan pakaian takwa Itulah yang paling baik. yang demikian itu adalab sebahagian dari tanda-tanda kekuasaan Allah, Mudah-mudahan mereka selalu ingat.” (Q.S. Al A'raf: 7: 26)

Jadi maksud pakaian yang terbuat dari bulu binatang yang dekat itu pun sudah terbiasa di ungkapakan dengan "menurunkan" maka tidak salah kalau Alquran yang dekat itu pun dikatakan dengan ungkapan "diturunkan". Sesuai dengan pengertian nuzulul yang diterangkan diatas, maka pengertian Nuzulul Qur'an artinya adalah turunya Alquran. Turunnya Alquran untuk yang pertama 
kalinya merupakan tonggak sejarah munculnya satu Syari'at baru dalam agama Tauhid yaitu agama Islam sebagai penyempurnah dari agama- agama Tauhid sebelumnya. Dan ayat-ayat didalam Alquran tidaklah diturunkan sekaligus secara keseluruhan, tetapi cara berangsur- angsur sesuai dengan ketentuan yang ada. Itulah sebabnya, ayat-ayat Alquran atau surat- suratnya yang diturunkan tidak sama jumlah dan Panjang pendeknya (Djalal, h. 47-48). Jadi, pengertian Nuzulul Qur'an menurut bahasa berarti "turunya Alquran". Dan secara istilah Nuzulul Qur'an adalah pemberitahuaan Allah tentang Alquran kepada segenap penghuni langit dan bumi dalam semua segi dan aspeknya (Al-Hafidz, 2008; 228).

Menurut Syekh Abd Al-Wahhab Abd Al- Majid Ghazlan yang dimaksud dengan nuzul adalah turunnya sesuatu dari tempat yang tinggi ke tempat yang lebih rendah dan sesuatu itu tidak lain adalah Alquran. Kemudian Syekh Ghazlan berkomentar, oleh karena yang turun itu bukan bentuk fisik, maka pengertian nuzul disini bisa mengandung pengertian kiasan, dan apabila yang dimaksud turun adalah lafaz, maka nuzul berarti Al-Ishal (penyampaian) dan (penginformasian) (Hermawan, 2011; 29-30)

Sedangkan secara etimologi pengertian Nuzul Qur'an berarti bacaan kerena makna tersebut diambil dari قرآن atau قرأ Secara terminologi yang dimaksud dengan Nuzulul Alquran adalah cara dan fase turunnya Alquran dari Allah SWT kepada Nabi Muhammad SAW. Seperti disebutkan dalam kitabkitab Alquran, bahwa sebelum diturunkan kepada Nabi Muhammad SAW, Alquran terlebih dahulu diturunkan Allah SWT ke Lauh Mabfudzh, kemudian dari Laub Mahfudz̧ diturunkan ke Baitul Izzah di langit dunia. Barulah dari Baitul Izzah Alquran diturunkan melalui perantara Malikat Jibril AS secara berangsur-angsur kepada Nabi Muhammad SAW (Az-Zarqani, 2000; 46). Alquran juga banyak diberikan pengertian oleh para mufassir, antara lain Ali Ash-Shobani menyatakan bahwa Alquran adalah firman Allah yang mu'jiz, diturunkan kepada nabi Muhammad melalui malaikat Jibril yang ditulis dalam Mushaf, diriwayatkan secara mutawatir, menjadi ibadah bagi yang membacanya, diawali dari Surah AlFatihah (Anwar, 2009; 13).

\section{Proses Turunnya Alquran}

Bukti dari keagungan Alquran bahwa ia turun dalam tiga kali, hal ini tidak dialami oleh Kitab Suci Samawi sebelumnya. Adapun yang dimaksud dengan tahap-tahap turunnya Alquran, ialah tertib dari fase-fase disampaikannya mulai dari sisi Allah SWT hingga kepada nabi Muhammad SAW. Kitab Suci ini tidak seperti kitab-kitab suci sebelumnya. Sebab, kitab suci ini diturunkan secara bertahap, sehingga betul-betul menunjukkan kemu'jizatannya. Disamping itu, penyampaiannya pun sangat luar biasa.

Turunnya Alquran yang pertama kali pada malam Lailatul Qadar merupakan pemberitahuan kepada alam tingkat tinggi yang terdiri dari malaikat-malaikat akan kemulian umat Muhammad. Tentang turunnya Alquran secara berangsur-angsur di jelaskan oleh Allah SWT dalam firmannya Surat Al Isra ayat 106:

"Dan Alquran itu telah Kami turunkan dengan berangsur-angsur agar kamu membacakannya perlahan-lahan kepada manusia dan Kami menurunkannya bagian demi bagian.” (Q.S.. Al Isra: 17/106)

Namun, turunnya Alquran secara berangsur-angsur itu mendapatkan celaan dari orang-orang kafir. Allah berfirman dalam Surat Al Furqan ayat 32: 
"Berkatalah orang-orang yang kafir; "Mengapa Alquran itu tidak diturunkan kepadanya sekalih turun saja? demikianlah supaya kami perkuat hatimu dengannya dan Kami membacakannya secara tartil (teratur dan benar)." (Q.S.. Al Furqan: 25/32)

Menurut anggapan orang-orang kafir maupun kaum musyrikin, kitab-kitab yang datang dari Tuhan, lazimnya diturunkan secara sekaligus. Mereka meragukan Alquran sebab diturunkannya dengan cara berbeda dengan penurunan kitab-kitab samawi lainnya. Sehingga mereka mengemukakan pertanyaan: Mengapa Alquran tidak diturunkan sekaligus? Untuk menjawab pertanyaan mereka, maka Allah SWT telah menjelaskan dalam ayat di atas (Q.S.. Al Furqan: 25/32) dimana di jelaskan bahwa salah satu hikmah Alquran diturunkan secara bertahap salah satunya untuk menguatkan hati Nabi dalam menerima dan menyampaikan kalam Allah kepada umat manusia (Az-Zarqani; 46).

Penyikapan terhadap nilai dan keyakinan dalam masyarakat Arab merupakan salah satu penyebab pewahyuan Alquran tidak di turunkan sekaligus, namun secara bertahap. Dengan rentang waktu tersebut maka pesan di dalam Alquran yang terdiri dari doktrin aqidah, norma syari'ah dan tuntunan moral (akhlak) tersampaikan secara bertahap. Dengan mengetahui hubungan pewahyuan ayat-ayat Alquran dengan realita sosial juga akan diketahui bahwa Alquran mempunyai hubungan historitas yang kuat dengan kondisi masyarakat tanpa menafikan dan mengurangi nilai wahyu ilahiya-Nya yang bersifat samawi (Ali Engineer; 1999: 43). Secara kronologis proses penurunan Alquran Al-Karim, diturunkan oleh Allah SWT kepada Nabi Muhammad dalam tiga fase (Rahmawati, 2013) sebagai berikut:

\section{Tahapan Pertama}

Tahapan pertama, penyampaian Alquran dari Allah kepada Laub al-Mahfǔh. Maksudnya, sebelum Alquran disampaikan kapada Rasulullah saw sebagai utusan Allah terhadap manusia, Alquran terlebih dahulu disampaikan kepada Lauh al-Mahfuzh, yakni suatu tempat lembaran yang terpelihara dimana Alquran pertama kali ditulis pada lembaran tersebut. Sebagian tafsir Lauh Mahfudz disamakan dengan Kitabin Maknun yang berarti "kitab yang terjaga". Akan tetapi secara umum Lauhil Makhfudh diartikan sebagai suatu tempat yang di dalamnya tersimpan segala sesuatu yang berkaitan dengan Qada dan Qodar Allah.

Tidak ada manusia yang tahu bagaimana cara penyampaian Alquran dari Allah ke Laub alMahfuг̧. Dan manusia tidak wajib mengetahuinya, tetapi wajib mempercayainya Sebagaimana firman Allah SWT:

"Tetapi ia (yang didustakan mereka) itu ialah Alquran yang mulia yang (tersimpan) dalam Laub al-Mabfurb." (Q.S.. Al-Buruj: 85/ 21-22)

Menurut Ibn Katsir Alquran berada di lauh mahfudz artinya berada di suatu tempat yang tinggi, yang dipelihara dari segala bentuk penambahan, pengurangan, pemalsuan, dan perubahan (Al-Hapizh, 1997, Juz 8; 373). Kapan dan bagaimana caranya Alquran diturunkan ke Lauh Mahfuzh adalah masalah ghaib-hanya Allah SWTT yang mengetahuinya. Ketika Alquran di lauh mahfudz, tidak ada yang tau persis bagaimana wujudnya. Hal itu dikarenakan lauhil mahfudh adalah alam yang tidak terjangkau oleh manusia. Sebagaian ulam berpendapat bahwa wujud Alquran di lauh mahfudz adalah berupa hapalan malaikat pendapat inipun masih diperdebatkan apakah hapalan berupa lapadz atau makna. Akan tetapi pendapat yang kuat adalah hapalan dalam bentuk lapadz yaitu dalam Bahasa Arab (As- Suyuti,1993; 41 43). Yang jelas, menurut Sayyid Quthub keberadaan Alquran terpelihara dan akan selalu menjadi 
rujukan akhir, yang mencakup segala persoalan dan kepadanya-Lah dikembalikan semua perkataan (Qutub, 1977, 6; 3876)

Menurut al-Zarqani Alquran diturunkan ke Lauh Mahfudzh sekaligus, tidak bertahap seperti tatkala diturunkan kepada Nabi Muhammad SAW. Argument az-Zarqani: Pertama, teks ayat sendiri menunjukkan hal itu. Kedua, tidak ada alasan Alquran harus diturunkan bertahap pada fase ini, karena hikmah diturunkannya Alquran secara bertahap tidak akan terwujud dan juga tidak diperlukan (Az zarqani; 36).

Adapun hikmah diturunkannya Alquran pada tahap pertama adalah hikmah keberadaan al-Lauh al-Mahfudzh itu sendiri sebagai batu tulis yang terjaga, yang diciptakan Allah untuk merekam dan mendokumentasikan apa-apa yang ada dan yang akan ada di hari akhir nanti. Selain itu, hikmah turunya Alquran tahap pertama sebagai wujud dari keinginan-Nya yang Maha Bijaksana, kemauan-Nya Yang Maha Pasti, kekuasan-Nya yang Maha Besar dan kekuatan-Nya yang tak tertandingi, semua ini akan menguatkan iman kita terhadap takdir dan qadha-Nya.

\section{Tahapan Kedua}

Tahapan kedua, turunnya Alquran ke langit pertama dengan sekaligus. Dilangit pertama itu, Alquran disimpan pada bayt al- izzah. Menurut pendapat yang shahih Baitul Izzah ini ada di langit yang paling bawah atau langit dunia. Hal ini di dasarkan atas Riwayat Ibn abbas berdasarkan firman Allah dalam surat Adh Dukhan ayat 3, yaitu:

"Sesunggubnya Kami menurunkannya pada suatu malam yang diberkabi [1369] dan Sesunggubnya Kami-lab yang memberi peringatan.” (Q.S.. Adh Dukhan: 44/3) (Yusuf, 2012; 16-17)

“Sesungguhnya Kami telah menurunkannya (Alquran) pada malam kemuliaan.” (Q.S.. Al Qadar: 97/1)

"Beberapa hari yang ditentukan itu ialab bulan Ramadhan, bulan yang di dalamnya diturunkan (permulaan) Alquran." (Q.S.. Al Baqarah: 2/185)

Ketiga ayat di atas menjelaskan bahwa Alquran diturunkan pada satu malam yang diberkahi, yaitu malam kemuliaan (lailatul qadar) dan malam itu adalah salah satu dari malam-malam Ramadhan. Menurut az-Zarqani yang dimaksud dengan turunnya Alquran dalam tiga ayat di atas bukanlah turunnya kepada Nabi Muhammad SAW secara berangsur-angsur 22 tahun lebih dan bukan hanya satu malam saja. Beberapa Riwayat yang sahih dari Ibn Abbas menjelaskan bahwa yang dimaksud adalah turunnya Al-Qur'an dari Laub Mahfudz̧h ke Bait al'Izzah di langit.

Ulama berbeda pendapat tentang bagaimana proses turun serta masanya. Pendapat pertama, yang dianut oleh Sebagian besar ulama ialah diturunkan sekaligus pada malam lail Al Qadar di bulan Ramadhan. Alasan yang menguatkan pendapat ini ialah ditemukannya bermacam hadits yang mendukung pernyataan itu diantaranya:

Riwayat Hakim

'Dari Sa'id ibn Jabir, dari Ibn Abbas, dia berkata "Alquran itu dipisabkean dari az-Diikr, lalu diletakan di Bait alIrzah di Langit Dunia; Maka Jibril As mulai menurunkannya kepada Nabi Mubammad SAW dan membacakannya secara tartil” 
Riwayat Nasa'I Hakim dan Baihaqi

"Dari Daud ibn Abi Hind, dari Ikrimah, dari Ibn abbas, dia berkata: Alquran diturunkan sekaligus ke Langit Dunia pada malam Qadar, kemudian diturunkan sesudah itu dalam 20 tabun. Kemudian dia membaca firman allah SWT dan Alquran itu telab kami turunkan dengan berangsur-angsur agar kamu membacakannya perlahan-lahan kepada manusia dari kami menurunkannya bagian demi bagian.” (Q.S.. Al Isra:106)

\section{Riwayat Hakim, Baihaqi dll}

"Dari Mansur ibn al-Mu'tamir, dari Sai'id ibn Jabir, dari Ibn Abbas RA, tentang firman Allah ("Sesungguhnya Kami telah menurunkannya Alquran pada malam kemuliaan." (Q.S.. Al Qadar: 97/1) dia berkata: Alquran diturunkan sekaligus pada malam Qadar ke Langit Dunia, tempat turunnya secara berangsur-angsur. Lalu Allah menurunkannya kepada Rasulullah SAW bagian demi bagian. Allah SW'T berfirman: ("Berkatalab orangorang yang kafir; Mengapa Alquran itu tidak diturunkan kepadanya sekali turun saja?” demikianlah supaya Kami perkuat hatimu dengannya dan Kami membacakannya secara tartil (teratur dan benar)). (Q.S.. Al-Furqan: 25/32)

Pendapat yang paling benar dari ketiga hadits di atas ialah pendapat ketiga, karena menurut Imam Syuyuti bahwa seluruh hadist ini sahih walaupun maukuf pada diri ibnu Abbas tapi ia memiliki identitas marfu' karena menurut ulama hadist apabila perkataan sahabat yang tidak diintervansi oleh logika dan Israiliat maka identitas hadist itu marfu' kepada Nabi Muhammad SAW. Dan ketiga riwayat Hakim, Nasa'I dan Baihaqi di atas yang menyatakan bahwa al-Qur'an diturunkan sekaligus ke Baitul'Izzah fi asSama'ad-Dunya pada malam qadar.

\section{Tahapan Ketiga}

Tahapan ketiga, Alquran diturunkan dari bayt al-izzah di Langit Dunia, kemudian di turunkan kapada Nabi Muhammad SAW pertama kali pada malam Qadar, tetapi turunnya tidak sekaligus melainkan sedikit demi sedikit menurut keperluan, masa dan tempat Nuzulul Qur'an. Adapun proses atau tahap yang ketiga ini ialah perantara malaikat Jibril atau juga sering di sebut dengan nama ruhul amin dari Baitul Izzah kepada Nabi Muhammad SAW di dalam Gua Hira (Mekkah). Ayat yang menerangkan tentang ini adalah firman allah dalam surat Al-Isra: 106, yaitu:

"Dan Alquran itu telah kami turunkan dengan berangsur-angsur agar kamu membacanya perlahan kepada manusia. Dan kami menurunkannya bagian demi bagian.”(Q.S. Al- Isra: 17/106)

Ayat di atas mengunakan kata turun yang merupakan Masdar dari kata menurunkan secara berangsur-angsur (Qathon, 1993; 57).

Menurut ulama asy-Sya'bi, sebagaimana dikutif al-Qaththan berpendapat-berbeda dengan pendapat Ibn Abbas di atas—bahwa tiga ayat (Q.S.. Adh Dukhan: 44/3; Al Qadar: 97/1 dan Al Baqarah: 2/185) tidaklah menunjukkan turunnya Alquran dari Laub Mahfudz̧h ke Baitul'Izzah di Langit Dunia, tetapi menunjukkan permulaan turunnya Alquran itu terjadi pada bulan Ramadhan. Sesudah itu diturunkan secara berangsur-angsur. Adapun keistimewaan bulan Ramadhan dan Lailatul Qadar yang merupakan malam yang diberkahi itu tidak akan kelihatan oleh manusia kecuali Rasulullah SAW (al-Qaththan,1976; 102).

Ayat yang pertama kali di turunkan kepada Rasulullah SAW-menurut pendapat yang paling popular dan kuat berdasarkan hadits Riwayat Bukhari dan Muslim dari Aisyah Ummul Mu'minin-adalah lima ayat pertama Surat Al-Alaq. 
Sesuai dengan kebutuhan, ada kalanya satu ayat, dua ayat, dan bahkan kadang-kadang satu surah. Dalilnya Surah Asy-Syu'ara' ayat 193-195:

"Dia dibawa turun oleh Ar-Ruh Al-Amin (Jibril), ke dalam hatimu (Muhammad) agar kamu menjadi salah seorang di antara orang- orang yang memberi peringatan, dengan bahasa Arab yang jelas.” (Q.S.. Asy-Syu'ara': 26/ 193-195)

Alquran diturunkan kepada Nabi Muhammad SAW melalui malaikat Jibril, tidak secara sekaligus, melainkan turun sesuai dengan kebutuhan. Bahkan, sering wahyu turun untuk menjawab pertanyaan para sahabat yang dilontarkan kepada Nabi atau untuk membenarkan tindakan Nabi SAW. Disamping itu, banyak pula ayat atau surat yang diturunkan tanpa melalui latar belakang pertanyaan atau kejadian tertentu (Anwar, 2012; 35-36)

\section{Hikmah Penurunan Al-Qur’an Secara Berangsur}

Kitab suci Al-Qur'an diturunkan oleh Allah SWT kepada Rasulullah SAW secara berangsurangsur dalam dua periode (Makkah dan Madinah). Periode Makkah (610-622M) di mulai pada malam 17 Ramadhan tahun 41 dari Milad Nabi sampai dengan 1 Rabi'al-Awwal tahun 54 dari Milad Nabi (12 tahun 5 bulan 13 hari). Ayat-ayat yang diturunkan oada masa itu kemudian di sebut ayat-ayat Makkiyah yang berjumlah 4.726 ayat dan terdiri atas 89 surat. Sedangkan periode Madinah (622-632 M) dimulai tanggal 1 Rabi'al-Awwal tahun 54 sampai dengan 9 Dzulhijjah tahun 63 dari Milad Nabi atau bertepatan dengan tahun ke-10 Hijrah ( 9 tahun 9 bulan 9 hari). Jadi total lama kedua periode tersebut adalah 22 tahun 2 bulan dan 22 hari. Ayat-ayat yang turun dalam periode ini dinamakan ayat-ayat Madaniyah, meliputi 1.510 ayat dan mencakup 25 surat.

Hikmah turunnya Alquran secara berangsur-angsur merupakan suatu metode yang berfaidah bagi kita untuk mengaplikasin kedua proses tersebut yang harus dilalui. Sebab turunnya Alquran secara berangsur dan bersifat alami itu dapat meningkatkan mutu Pendidikan bagi umat Islam untuk memperbaiki jiwa manusia, meluruskan prilakunya, membentuk kepribadian dan

menyempurnahkan eksistensinya sendiri.

Sebagaimana yang kita ketahui segala sesuatu yang Allah kehendaki itu mengandung hikmah dan memiliki tujuan. Begitu juga dengan proses turunnya Al-Qur'an secara bertahap. Diantara hikmah atau tujuannya adalah sebagai berikut: (Rahmawati, 2013; 19)

Pertama, Untuk menguatkan hati Nabi Muhammad Saw dalam menerima dan menyampaikan kalam Allah kepada umat manusia. Dalam melaksanakan tugasnya, Rasulullah sering menghadapi hambatan dan tantangan. Di samping itu dapat juga menghibur hati beliau pada saat menghadapi kesulitan, kesedihan atau perlawanan dari orang-orang kafir

Kedua, Merupakan mukjizat bagi Nabi untuk menjawab dan mematahkan tantangan orang-orang kafir. Sering kali mereka (orang kafir) mengajukkan pertanyaan-pertanyaan dengan maksud melemahkan dan menantang juga menguji kenabiaan Rasulullah. Mereka pernah menyakan tentang kiamat kapan datangnya.

Ketiga, Memudahkan Nabi dalam menghafal lafadz Alquran, mengingat Alquran bukan sya'ir atau prosa tetapi Kalam Allah yang sangat berbobot isi maknanya sehingga memerlukan hapalan dan kajian 
secara khusus. Dan untuk membacanya kepada umat serta menjelaskan dan memberikan contohcontoh pelaksaannya. Jika Alquran diturunkan sekaligus tentu akan memberatkan Nabi jika harus membacakan dan menjelaskannya.

Keempat, Memudahkan umat pada masa itu untuk menghafal, mencatat dan memahami Alquran. Turunya Alquran secara berangsur memudahkan Nabi untuk menghafal dan memahaminya, terutama Nabi sangat takut apabila Alquran tidak menetap di hatinya. Hal ini berdampak positif bagi umatnya, karena pada masa Nabi menulis dan membaca sangat langka. Mereka menghandalkan kekuatan akal dalam menghafal

Kelima, Untuk memberi kesempatan sebaik-baiknya kepada umat Islam untuk meninggalkan sikap mental atau tradisi-tradisi jahiliyah yang negative secara berangsur- angsur

Keenam, Menjawab problematika masyarakat. Hal ini menerangkan apa-apa yang di butuhkan masyarakat sesuai dengan kondisi dan problema yang mereka hadapi.

Ketujuh, Mengetahui nasikh dan Mansukh dalam ayat Alquran yang berkaitan dengan hukum.

Kedelapan, Memberikan pengaruh yang besar dalam proses dakwah Islam dan pembentukan umat. Pada periode Mekkah diturunkan lebih dahulu ayat-ayat yang berhubungan dengan Tauhid dan keadilan social. Barulah pada perioe Madinah di turunkan ayat-ayat tentang hukum dalam belbagai aspek kehidupan, baik hukum keluarga, harta benda, pidana dan pemerintahan. Ayat-ayat hukum pun di turunkan secara bertahap sesuai dengan kondisi masyarakat pada waktu itu (Supiana \& Karman, 2002; $58)$.

Faedah ekternal lainnya adalah untuk mempermudah manghafal bagi para pengikut Nabi yang Sebagian besar tidak bisa menulis. Gradualisasi turunnya wahyu memberi gambaran yang sangat penting bahwa tatanan yang hendak dibangun oleh Alquran bukanlah merupakan paket sekali jadi yang absolut tapa melalui proses responsive dan terpisah dari perkembangan sosio-politik yang ada. Meskipun Alquran merupakan sumber hukum, namun dalam kenyataannya Alquran bukanlah sebuah dokumentasi hukum yang langsung dapat di adopsi.

Dalam kajian Nuzul Qur'an sangat penting untuk membuktikan bahwa Alquran memang benarbenar berasal dari Allah SWT, bukan karya Nabi Muhammad SAW. Kajian ini merupakan bagian dari bukti otentisitas dan validitas Alquran. Keyakinan terhadap otentisitas dan validitas Alquran sangat penting dan urgen bagi seorang Muslim karena menyangkut keimanan kepada sumber utama ajaran Islam.

\section{Penutup}

Mempelajari kesejarahan turunnya Alquran merupakan bagian penting dalam memahami pesan yang terkandung dalam Alquran secara utuh dan menyeluruh. Sejarah sebagai sumber ilmu pengetahuan mengungkapkan peristiwa masa silam. Sejarah turunnya Alquran mengindikasikan penalaran kritis dan usaha cermat untuk mencari kebenaran suatu penjelasan teantang sebab dan asal-usul turunnya ayatayat Alquran yang diamanahkan pada Nabi Muhammad SAW. Selain itu juga dalam mempelajari sejarah Alquran berarti bersinggungan dengan periodesasi dan rekontruksi proses genesis perubahan dan perkembangan dari turunnya Alquran. 
Pengertian Nuzulul Qur'an secara istilah adalah Peristiwa diturunkannya wahyu Allah SWT (Alquran) kepada Nabi Muhammad SAW melalui perantara Malaikat Jibril AS secara bertahap. Alquran diturunkannya melalui tiga fase atau tahapan. Tahap pertama, Alquran diturunkan / ditempatkan ke Laub Mahfudh. Kedua Alquran turun dari Lauh Mahfudh ke Baitul izzabdi Langit dunia. Ketiga, Alquran turun dari Baitul Izzah dilangit dunia langsung kepada Nabi Muhammad SAW.

Ayat-ayat Alquran tidaklah diturunkan sekaligus secara keseluruhan, tetapi secara berangsurangsur. Surat-surat yang diturunkanya pun tidak sama jumlah panjang dan pendeknya, terkadang diturunkan sekaligus secara penuh dan terkadang sebagianya saja. Dengan diturunkanya Alquran secara berangsur- angsur banyak hikmah yang akan diperoleh yaitu menetapkan hati Rasulullah, melemahkan lawan-lawannya, mudah difahami dan dihafal, penyusunannya akan sesuai dengan lalulintas peristiwa atau kejadian.

Hikmah Diturunkannya Alquran Secara Bertahap yaitu: Untuk menguatkan hati Nabi Muhammad Saw; Supaya mudah dihafal dan dipahami; Supaya orang-orang mukmin antusias dalam menerima Qur'an dan giat mengamalkannya; Mengiringi kejadian- kejadian di masyarakat dan bertahap dalam menetapkan suatu hukum; Untuk melemahkan lawan-lawannya (mukjizat; Untuk menantang orang-orang kafir yang mengingkari Alquran

\section{Daftar Pustaka}

Al-Hapizh 'Imad ad-Din Abu- al-Fada'Ismail Ibn Katsir al-Qurasyi ad-Dimasyqi, Tafsir al- Qur'an alAzhim, Riyadh: Dar alam al- Kutub, 1997, Juz 8

Ahsin W. Al-Hafidz, Kamus Ilmu Al-Qur'an, (Jakarta: Amzah, 2008)

Anwar, Abu, Ulumul Qur'an, (Jakarta: Amzah, 2009)

Anwar, Rosihoh, Ulum Al-Quran, (Bandung: Pustaka Setia, 2012)

Ash-Shabuni, Muhammad Ali, At Tibyan Fi Ulumul Qur'an (Trj. Muhammad Qadirun Nur, Ihktisar) Ulumul Qur'an Praktis, (Jakarta: Pustaka Amani)

As-Suyuti Jalaludin, Luababun dan Asbabun Nuzul, (Semarang As-Syifa: 1993)

Athaillah, H. A., Sejarah AlQuran, (Yogyakarta: Pustaka Pelajar, 2010)

Al-Qaththan, Manna, Mabahits Fi Ulum Al-Qur'an, (Riyadh: Muassasah ar-Risalah, 1976)

Az-Zarqani, Manahil al-Irfan fi Ulum Al-Qur'a, 1:34; Abdul Djalal, Ulumul Qur'an, (Surabaya: Dunia Ilmu, 2000)

Baidan, Nasthruddin, Wawasan Baru Ilmu Tafsir, (Yogyakarta: Pustaka Pelajar: 2005)

Chirizin, Muhammad, Al-Qur'an dan Ulumul Qur'an, (Jakarta: Dana Bakhti Prima Yasa, 1998)

Djalal, Abdul, Ulumul Qur'an, (Surabaya: CV Dunia Ilmu) 
MIMBAR Agama Budaya, 38 (1), 2021

Engineer, Asghar Ali, Asal Usul dan Perkembangan Islam, (Yogyakarta: Pustaka Pelajar, 1999)

Hermawan, Acep, Ulumul Quran, (Bandung: PT. Remaja Rosdakarya, 2011)

Madya, Ahmad Syans, Peta Pembelajaran Al-Qur'an, (Yogyakarta: Pustaka Pelajar, 2008)

Qathon, Mana’ul, Mabahis Fi Ulum Al-Qur'an, (Jakarta: PT. Rineka Cipta, 1993)

Qutub, Sayyid, Fi Zhilal Al-Qur'an, (Beirut: Dar asy-Syuruq, 1977), jilid 6

Rahmawati, Mohammad Gufrondan, Ulumul Qur'an: Praktis dan Mudah, (Yogyakarta: Teras, 2013)

Supiana \& Karman, Ulumul Qur'an, (Bandung: Pustaka Hidayah, 2002)

Wahid, Marzuki, Study Al-Qur'an Kontemporer, Prespektif Islam dan Barat, (Bandung: Pustaka Setia, 2005)

Yusuf, Kadar M, Studi Alquran, (Jakarta: Amzah, 2012) 